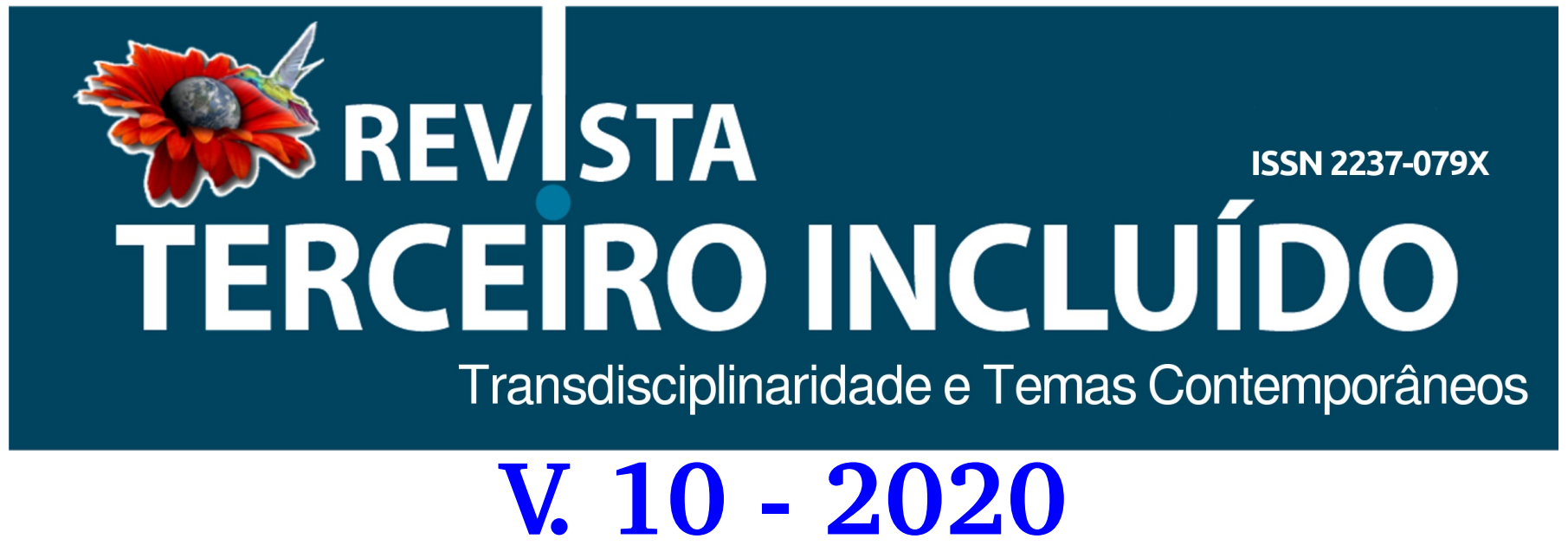

Antônio ROCHA

O Cenário Político Brasileiro E A Polarização Dos Últimos Tempos. pp. 159-173

DOI: 10.5216/teri.v10i1.67235 


\title{
O CENÁRIO POLÍTICO BRASILEIRO E A POLARIZAÇÃO DOS ULTIMOS TEMPOS.
}

\section{EL ESCENARIO POLÍTICO BRASILEÑO Y LA POLARIZACIÓN DE LOS ULTIMOS TIEMPOS.}

\author{
THE BRAZILIAN POLITICAL SCENARIO AND THE POLARIZATION \\ OF RECENT TIMES.
}

Antônio ROCHA

\section{RESUMO:}

A reflexão apresentada neste artigo é fruto de um estudo bibliográfico e tem como objetivo proporcionar ao leitor reflexões em torno da polarização política no Brasil, mas ao mesmo tempo sinalizar que o contexto é mais amplo, de caráter global. Os referenciais ajudam contrastar fatos e realidades tomando como base à sociologia, complementados por outros referenciais. Trata-se de uma análise que, mesmo na superficialidade do contexto histórico, tem importância ímpar a ajudar o leitor que está em busca de um raciocínio crítico sobre a realidade vivida no país, nos últimos tempos. 0 estudo perpassa por momentos na história, de controle, mas também, de reações sociais. Apesar de não entrar na especificidade do tema, o estudo se vale de referenciais com abordagens em diferentes momentos na história. Além da Origem social e Antropológica do brasileira, ele fala no sistema estrutural e evolutivo da nação, na polarização dos últimos tempos capaz de envolver, de um lado, uma elite que fala em democracia, mas busca a privatização do Estado, o extermínio de ações sociais e a concentração da riqueza para uma minoria, do outro, seguimentos sociais e partidos de esquerda em defesa da democracia e ações sociais, além da preservação e proteção do Estado. Mesmo não entrando no mérito da questão polêmica, o estudo quis servir como provocação à reflexão. Outra evidência no artigo que merece a atenção, é a proposta de reflexões, valorização e o cuidado com a chegada da tecnologia e seus desafios para ambos os polos. As conquistas tecnológicas podem representar benefício, recurso e/ou comprometimento, um sustentáculo à polarização ideológica mencionada, mas pode prover indagações e manipulações em torno da realidade de toda a história do país. Enfim, sugere-se que o leitor busque entender a dimensão histórica e social do país para aprimorar sua compreensão em torno do comportamento social e psicológico do cidadão brasileiro. 0 momento de incerteza com a pandemia (Covid 19) neste ano de 2020 pode fomentar uma reflexão e um novo paradigma social, aproximar as pessoas e direcioná-las a uma mudança de comportamento mais relevante, em defesa do social, do humano.

PALAVRAS-CHAVE: Ideologia; Polarização; Psicologia; Tecnologia.

\section{RESUMEN:}

La reflexión presentada en este artículo es el resultado de un estudio bibliográfico y tiene como objetivo brindar al lector reflexiones sobre la polarización política en Brasil, pero al mismo tiempo señala que el contexto es más amplio, de carácter global. Las referencias ayudan a contrastar hechos y realidades basados en la sociología, complementados con otros. Es un análisis que, aun en la superficialidad del contexto histórico, tiene una importancia sin igual para ayudar al lector que busca en el país recientemente. El estudio pasa por momentos de la historia del control, pero también de las reacciones sociales. Aunque no entra en la especificidad del tema, el estudio utiliza referencias con enfoques en diferentes momentos de la historia. Además del origen social y antropológico de los brasileños, se habla del sistema estructural y evolutivo de la nación, de la polarización de los últimos tiempos capaz de involucrar, por un lado, a una élite que habla de democracia, pero busca la privatización del Estado, el exterminio de acciones sociales y concentración de la riqueza en minoría, por el otro, segmentos sociales y partidos de izquierda en defensa de la democracia acciones sociales, además de la preservación y protección del Estado. El estudio no pretendía ahondar demasiado en los méritos del controvertido tema, pero sí sirvió para provocar una reflexión. Otra evidencia en el artículo es la propuesta de reflexión, valoración y cuidado con la llegada de la tecnología y sus desafíos para ambos polos. Los logros tecnológicos pueden representar beneficio, recurso y/o compromiso, un apoyo a la polarización ideológica antes mencionada capaz de plantear interrogantes y manipulaciones en torno a la realidad y toda la historia del país. Finalmente, se sugiere que el lector busque comprender la dimensión histórica y social del país para mejorar su comprensión del comportamiento social y psicológico del ciudadano brasileño. El momento de incertidumbre con la pandemia (Covid 19), en este año de 2020 puede propiciar la reflexión sobre un nuevo paradigma, acercando a las personas y dirigiéndolas hacia un cambio de comportamiento más relevante en defensa de lo social y humano.

PALABRAS CLAVE: Ideología; Polarización; Psicología; Tecnología.

\section{ABSTRACT:}

The reflection presented in this article is the resulto $f$ a bibliographic $s$ tudy and aims to provide the reader with reflections on political polarization in Brasil, buta the same time it signals that the contexto is broader, of a global character. The references help to contrast facts and realities based on sociology, complemented by others. It is an análisis that, even in the superficiality of the historical context, has unparalleled importance in helping the reader who ie looking for a critical reasoning about the reality experienced in the country recently. The study goes through moments in the history of control, but also of social reactions. Although it does not go into the

1 Mestre em Ciências da Educação - UNADES - Paraguai. Especialização em Ciências de Educação - FAP - ES. Especialização em Filosofia da Educação - FAP - ES. Especialização em Didática e Metodologia do Ensino Superior - UNIOURO - RO. Licenciatura Plena em Pedagogia - UNIR - RO e Técnico em Agropecuária. 
specificity of the theme, the study uses references with approaches at different times in history. In addition to the Brazilian social and anthropological origins, there is talk of the structural and evolutionar system of the nation, of the polarization of recent times capable of involving, on the one hand, na elite that speaks of democracy, but seeks the privatization of the State, the extermination of social actions and the concentration of wealth in a minority, on the other, social segments and leftwing parties in defense of democracy social actions, in addition to the preservation and protection of the State. The study did not aim to delve too much into the merits of the controversial issue, but it did serve to provoque reflection. Another evidence in the article is proposal for reflections, valuation and care with the arrival of technology and its challenges for both poles. Technological achievements can represent benefit, resource and/or commitment, a support to the aforementioned ideological polarization capable of providing questions and manipulations around the reality and the entire history of the country. Finally, it is suggested that the reader seeks to understand the historical and social dimensión of the coutry to improve its understanding of the social and psychological behavior of the Brazilian citizen. The momento $f$ uncertainty with the pandemic (Covid 19), in this year of 2020 can foster reflextion on a new paradigma, bringing people together and directiong them to a more relevant behavior change in defense of the social and human.

KEYWORDS: Ideology; Polarization; Psychology; Technology.

\section{INTRODUÇÃO}

O presente artigo tem como finalidade descrever o Brasil em sua formação Antropológica perpassando pelos caminhos trilhados na estruturação social, política e ideológica. Trata-se de um estudo bibliográfico de caráter crítico que procura desconstruir muito do que foi ensinado nos Livros Didáticos trabalhados nas escolas. Ele vem mostrar aquilo que não se vê sem um olhar crítico, sem a busca consistente. Serve para contrapor o heroísmo que sempre foi muito forte e manipulador da real situação da maioria dos brasileiros. Os confrontos ideológicos sempre existiram nesse país, bem como, as distorções da realidade, mas pouco a pouco os cidadãos foram ganhando a consciência de que são seres humanos e compõem esta realidade.

De origem semifeudal e escravocrata, esteve presente em seu seio, o autoritarismo de um lado e a submissão do outro, o confronto, mas também a punição dos que desobedeciam a ordem. Uma classe instruída, outra analfabeta ou, semianalfabeta. Porém a necessidade evolutiva da industrialização e urbanização, obrigou o país a investir no conhecimento. Aquilo que antes foi privilégio dos bacharéis, a educação dos filhos dos senhores das casas grandes, passaria agora à sociedade, uma educação propícia à obediência, evidentemente. Nasceu a primeira oportunidade de instruir o filho dessa nação, mesmo que, essa educação caracterizasse dois polos, uma escola para a elite instruindo o domínio e a outra ao cidadão instruindo à obediência.

Nem todo ser é carrasco do outro e, naturalmente, surgiu na sociedade seres pensantes com caráter humano capazes de defender os indefesos do país. Há aquele que, pela criatividade, ou pela sorte mesmo, chega ao status de poder e não perde seus princípios e assume a defesa dos seus. É aí que o embate ideológico se instaura, há no país os que visam o domínio, mas também, os que querem libertação dos seres humanos como dignos de ser gente. Assim acontece o início do embate social, as organizações sociais no país, a luta pela democracia e direitos iguais. Por mais que o sistema persegue e pune, em nome da ordem, a criatividade humana supera as amarras instauradas para forçar a obediência civil e desmascara a moralidade impetrada pelo sistema, que na maioria das vezes, é antiética.

Com o advento e popularização dos instrumentos tecnológicos, o sistema passou a mapear os interesses da população, mas também possibilitou a comunicação, facilitando à instrução para a libertação. Atualmente, existe uma elite local que quer a todo custo monopolizar as pessoas, ela é financiada política, econômica e ideologicamente por uma elite global que popularizou a comunicação 
para o mapeamento do comportamento humano, mas estes instrumentos para o mapeamento humano, sãos os mesmo que possibilitam a disseminação e instrução dos entes manipulados. É preciso saber usá-los! São estas opiniões que vão conduzir você no artigo. Ele busca desconstruir o sistema de distorções, canalizando as informações em direção ao real. Depois de mais de cinco séculos, onde uma maioria passou adormecida é preciso despertar a consciência de que o país é rico e merece uma população alegre e feliz.

\section{ORIGEM SOCIAL E ANTROPOLÓGICA DO BRASILEIRO}

De origem e estruturação social semifeudal constituída por três bases principais: a indígena, a africana e a europeia, somos uma nação heterogênea do ponto de vista antropológico. No caráter econômico e político, predominou uma minoria com grandes privilégios, controlando uma maioria sujeita a muitas atrocidades. Do ponto de vista ideológico, a nação demorou a despertar e os poucos que desafiou o poder sempre foram intimidados, punidos ou, de forma mais dramática, até exterminados da sociedade. Politicamente falando, o país passou por muitas conquistas e evoluções rumo ao campo democrático, muitas vezes avançado, outras vezes retrocedendo na história.

o primeiro grande esforço apresentado aqui está em sintetizar o contexto histórico brasileiro dos mais de cinco séculos, em poucos parágrafos. Não se trata de detalhar cada comportamento social, ou desmistificar fatos históricos acontecidos em determinada região do país, mas trata-se de situar o leitor no contexto que parece mais condizente com a realidade muitas vezes demonstrada no regime tradicional com heroísmo e distorção da realidade. Estamos falando da exploração indígena e seus descendentes, mas também da africana e seus descendentes. A dramática realidade vivida por esses povos, por mais se camufle essa realidade nos livros didáticos, é impossível escondê-la da história, basta ter uma experiência de vida.

Quando se busca aprofundar nas reflexões em obras disponíveis, tanto do passado, como no presente, as evidências deixam escapar a cruel veracidade. Como já foi sinalizado, os três segmentos importantes para a formação do povo brasileiro, se deu, com a chegada dos europeus e dos africanos que, confrontado e, afrontando à cultura nativa, deu origem a essa nação que é plural e cativante. Plural em sua dimensão étnica e cativante na sua forma cultural de ser. Ideologicamente falando, esta mesma população se diverge em determinados momentos e converge em outros regulando o sistema político que na maioria das vezes é ideologicamente usado por uma elite controladora.

Para que você se situe melhor ao que estamos propondo refletir aqui, buscamos perpassar por alguns momentos históricos importantes a ajudar no entendimento da realidade brasileira. Inicialmente, é preciso perceber que o sistema de colonização semifeudal e escravocrata foi o método que o colonizador achou mais adequado para a nova Colônia, mais tarde ele foi direcionado à urbanização e, consequentemente, à industrialização. Nasce os polos brasileiros, um privilegiado e o outro, sujeito à subordinação. São essas duas vertentes que continuam presentes e em busca de garantir seu espaço social. Enquanto um detém o controle político-social e os meios de produção, o 
outro compõe-se da força de trabalho, mas reivindica direitos à expansão social gerador do contraste ao qual estamos falando, a polarização.

\section{SISTEMA SEMIFEUDAL E ESCRAVOCRATA.}

Utilizando-se da contribuição de autores que são importantes para desmistificar o Brasil que muitos não veem, o artigo esforça-se para ser criativo, claro e objetivo. Portanto, busca-se nos primeiros referenciais que serão apresentados, dialogar no texto, proporcionando ao leitor reflexões pertinentes ao tema envolvendo no debate novos referenciais que, também são importantes para entender a temática. Em Darcy Ribeiro (1995), viu-se a formação, como diria o sociólogo, a gestação de um povo nação. Em "O Povo Brasileiro," ele mostrou que a Ilha chamada Brasil gestou um povo que difere dos povos originário, mas também difere do colonizador, e, ao mesmo tempo possui traços de ambos, até porque essa nação é uma mescla de um tripé inicial com o europeu, o africano e os povos originários, além de influências do Continente asiático.

Por sua vez, o segundo referencial explorado no artigo, é importante na fundamentação e no entendimento da transição rural/urbano, na mudança de comportamento social do sistema escravocrata rural para o industrial, consequentemente, burocrático e urbano. Estamos falando em Gilberto Freyre e a obra "Sobrados e Mucambos (2013)". Se o primeiro referencial fala na gestação da nação, o segundo complementa-o com a estruturação social refletindo a transição do modelo de sociedade inicial rural para a superação colonial de regime semifeudal. Enquanto o primeiro autor utiliza-se muito fortemente da visão antropológica para chegar ao campo social e apresentar a sua visão sociológica, o segundo, observa a estrutura social e a evolução dos mecanismos burocráticos estruturados, endossados pelos Bacharéis em sua dimensão sociológica.

Outro autor importante para a reflexão, capaz de atualizar o contexto que estamos discutindo aqui, também se vale da sociologia. Ele sintetiza a história brasileira da escravidão à lavajato no livro: "A Elite do Atraso: da escravidão à lava-jato (2017)". Também contribui fortemente para o entendimento do Brasil que não queremos, o Brasil da "Ralé - expressão do autor", em “Subcidadania brasileira: para entender o país além do jeitinho brasileiro (2018)". Evidentemente, não se trata aqui de discutir as referidas obras, ou criar um debate crítico em torno dos autores, mas sim, se valer das suas análises para o entendimento do que queremos dialogar no artigo.

o que se pretende, nada mais é que, refletir o "Cenário Político brasileiro em sua versão mais polarizada da história". Para alguns cidadãos, o momento é assustador e desgovernado, porém observando em viés crítico, percebe-se que positivamente, o país em sua base social, está amadurecendo. A representatividade ideológica sobre o social está equiparada em seu nível estrutural com representação do campo econômico, industrial/urbano e rural, mas também, está representada nas camadas da sociedade onde se tem a força de trabalho, onde havia o controle e a submissão, esses setores têm reagido, daí a polarização na representatividade. Não há uma anormalidade, o país cresceu em consciência e esse choque identitário é a causa dos transtornos nos momentos de polarização.

No Brasil, de índios e negros, a obra colonial de Portugal também foi radical. Seu produto verdadeiro não foram os ouros afanosamente buscados e achados, nem as mercadorias 
produzidas e exportadas. Nem mesmo o que tantas riquezas permitiram erguer o velho mundo. Seu produto real foi o povo-nação, aqui plasmado principalmente pela mestiçagem, que se multiplica prodigiosamente como uma morena humanidade em flor, à véspera do seu destino. (RIBEIRO, 1995, p. 68).

Veja como Darcy Ribeiro descreve o Brasil e o seu potencial humano. Enquanto, costumeiramente, as pessoas se voltam para o econômico, para a riqueza material, na citação representada acima, viu-se que Ribeiro focou na riqueza antropológica, identitária. Obviamente, sabia ele dá importância dos outros mecanismos que proporcionam as riquezas de uma nação, tanto quanto, sabemos disso, mas nos valemos da reflexão, pois o foco no artigo volta-se para a formação social e queremos chegar ao cenário político brasileiro com a sua polarização. A bela nação descrita pelo autor, bela no sentido de beleza estética mesmo, mas também no sentido crítico, criativo, para sobreviver, precisou de muitos embates ideológicos que proporcionasse a consciência social mais igualitária, uma situação ainda em jogo.

O autor da obra "O Povo Brasileiro (1995), deixa claro que nem tudo foi embate e que, o início no processo colonial houve a cordialidade dos nativos, bem como, dos futuros carrascos desses “inocentes", no entanto, com o passar dos tempos os conflitos começaram e se deram em vários níveis, como no biótico, no ecológico e na disputa por terras e riquezas, além do econômico e social. No plano étnico-cultural gestou uma nova etnia com a unificação da linguagem e dos costumes aqui perpetrados, porém predominou o regime autoritário escravocrata por quase quatro séculos e esses contrastes desfecham no cenário atual polarizado no país.

E, por essa razão, é importante estudar as obras de Gilberto Freyre "Casa Grande e Senzala" e "Sobrados e Mucambos", pois elas vêm para clarificar o processo de estruturação desses povos e a transição do modelo rural para o urbano/industrial e, consequentemente, o burocrático. Na segunda obra de Freyre, Jessé Souza mostra que: “O que Gilberto Freyre reconstrói em Sobrados e Mucambos é o início do Brasil moderno, ou seja, o Brasil a partir de 1808, que passa a ser o centro do império português e que se abre comercialmente à Europa. ... (SOUZA, 2017, p. 57). Se trata de um Brasil em processo de mudanças substanciais, um Brasil com mais de três séculos de existência onde uma minoria não tinha privilégios algum, como mostra a citação abaixo.

\footnotetext{
No Brasil, desde o ano zero, a instituição que englobava todas as outras era a escravidão, que não existia em Portugal, a não de modo muito tópico e passageiro. Nossa forma de família, de economia, de política e de justiça foi toda baseada na escravidão. Mas nossa autointerpretação dominante nos vê como continuidade perfeita de uma sociedade que jamais conheceu a escravidão a não ser de modo muito datado e localizado. (SOUZA, 2017, p. 40).
}

Observando a citação em Souza é perceptível que a escravidão foi preponderante desde o início colonial, algo que não existia na Metrópole, como nos mostra o próprio autor e por isso, ele diz, que: "Nosso desenvolvimento histórico foi diferente do europeu ..." Souza (2017, p. 47). Com a ação culminando na exploração escrava, os escravos sentem-se na obrigação de criar mecanismos para a sua defesa e aí vão nascendo os focos de resistências, até se chegar à formação dos Quilombos e tantos outros mecanismos que deram rumo à abolição em 1888 e consequentemente o advento da República em 1889. Para entender melhor o que estamos discutindo aqui, vamos adentrar no processo de industrialização e urbanização do país para você entender os mecanismos que impulsionam, mas também, que intimidam a sociedade da polarização apontada no título do trabalho. 


\title{
TRANSIÇÃO RURAL/URBANO E INDUSTRIALIZAÇÃO
}

Se no Brasil colonial havia uma Aristocracia que monopolizava o contexto daquela sociedade, no plano industrial e urbano, desde de sua origem predominou uma elite e, Jessé Souza é crítico a esta estrutura da sociedade brasileira atual. Se antes o poder era centrado no patriarca em sintonia ao Monarca, com a abolição e o advento da República o trâmite passou ao Estado burocrático. A sociedade, por sua vez, continuou se articulando e com muito sacrifício, foi encontrando alternativas. No entanto, o momento direciona a elite local à busca pelo controle social em detrimento do poder econômico global. Se sentindo ameaçada com as conquistas sociais das últimas décadas, a elite reage, pois a sociedade civil procura, cada vez mais, se mobilizar e exigir muitos direitos sociais que, até então, não eram reivindicados.

Desse modo, a urbanização representou uma piora nas condições de vida dos negros livres e de muitos mestiços pobres das cidades. O nível de vida baixou, a comida ficou pior e a casa também. Seu abandono os fez, então, perigosos, criminosos, maconheiros, capoeiras, etc. (SOUZA, 2017, p. 61).

Esta é a origem dos problemas sociais que não são bem esclarecidos quando se discute a razão social das coisas. Ao falar sobre campo e cidade proferido por Freyre, Souza descreve a piora nas condições de vida. Vê-se que o Brasil escravocrata que causou tantos transtornos de ordem física e psicológica, é o mesmo Brasil dos transtornos psicológicos da atualidade. 0 que difere um Brasil do outro, é a forma de exploração, os estímulos. Se antes não havia roupa, calçado, ou moda, hoje há um bombardeio psicológico com inovações a todo dia. Se antes a educação não era objeto de preocupação social, hoje se discute a educação e o professor é cobrado a dar resposta, mesmo sendo ludibriado com uma história que não condiz com a realidade do seu país.

O que se vê nos argumentos atuais é a condenação do Estado e segundo Souza (2017), isso serve para encobrir a elite real, a elite real, na verdade, está fora dele. Ela captura seus interesses e o condena em suas ações para encobri-la. Para o crítico, é a forma de imbecilizar e distorcer a realidade. Enquanto as pessoas focam no Estado como responsável pelo desmando social, o poder real se safa em sua ação e, esse jogo, é bastante emblemático para um leigo. Quanto aos que percebem o jogo e reage, ou começam a despertar para a realidade, são vistos como os oponentes, como o polo oposto à polarização de quem monopoliza a maioria.

\begin{abstract}
A primeira coisa a se fazer quando se reflete sobre um objeto confuso e multifacetado como o mundo social é perceber as hierarquias de questões mais importantes a serem esclarecidas. Sem isso, nos perdemos na confusão. A questão do poder é a questão central de toda a sociedade. A razão é simples. É ela que nos irá dizer quem manda e quem obedece, quem fica com os privilégios e quem é abandonado e excluído. $O$ dinheiro, é uma mera convenção, só pode exercer seus efeitos porque está ancorado em acordos políticos e jurídicos que refletem o poder relativo de certos estratos sociais. (SOUZA, 2017, p. 11).
\end{abstract}

Veja que o autor mostra, o que ele chama de "objeto confuso e multifacetado", como acontece na sociedade atual, é a razão mais óbvia, as hierarquias. Se existe quem manda, é evidente que existe um sujeito que obedece, ou deve obedecer. Todo o desobediente foge à regra moral que é imposta pelo sistema, mas condenada por Dussel em "Ética Comunitária” desde sua publicação em 1986. Para esse filósofo: “... O ético não é regido pelas normas morais, pelo que o sistema indica como 
bom..." (DUSSEL, 1986, p. 63). É na ação moral, que na verdade é relativa, segundo o cidadão da Argentina, que surge a margem ao poder para punir, como antiético, aquele que desobedece a ordem moral vigente.

\section{POLARIZAÇÃO}

Quanto à polarização expressamente dita, não se pretende discutir conceitos, ou razões, mas há uma situação que merece ser analisada. Trata-se dos excessos e, neste caso, os excessos podem se dar nos dois polos. Se afirmamos que o cenário político brasileiro carrega consigo uma polarização, é evidente que esses excessos podem contribuir para situações adversas, podendo ser útil, ou indesejável a qualquer um, independentemente de ele estar em um polo, ou no outro. Usando a razão se percebe que qualquer excesso não ajuda, é perigoso e gera maior resistência aos oponentes. 0 exagero pode estar na cicuta tomada pelo filósofo Sócrates, ou em uma pressão psicológica, ideologicamente pensada, para prejudicar qualquer ser humano, não importa a época, ou a circunstância.

Do ponto de vista político/ideológico o país vive o dilema entre duas forças conflitantes. De um lado, partidos de esquerda defendem a socialização, democratização e a valorização do Estado como mecanismo alternativo à sociedade. $\mathrm{E}$, do outro, partidos de direita defendem a concentração do poder, uma democratização dentro dos padrões elitistas e a desestruturação do Estado em razão do interesse privado. Quanto à população, os que se sentem mais instruídos, politicamente falando, se dão ao direito do embate ideológico e, a maioria desinformada sobre o real contexto social, não sabem a que caminho seguir e, portanto, essa maioria pode beneficiar a uma tendência, ou condená-la de acordo com o poder de convencimento do seu oponente.

\footnotetext{
A paixão pode ser irracional, mas a manifestação dela, não. Loucos por futebol! o perigo está no louco, pois há o perigo de a paixão se tornar fanatismo, de o conflito se transformar em confronto. A divergência é admissível, e até desejável, mas ela nunca pode conduzir à anulação do outro, daquele que pensa diferente de você. (CORTELLA, 2017, p. 55).
}

Utilizamos a citação em Cortella (2017), para exemplificar um tipo de excesso que pode ser irracional, segundo o filósofo brasileiro. Não estamos pensando a paixão em um contexto amoroso, mas também pode o ser. Nosso objetivo com este raciocínio é mostrar o perigo da paixão que pode chegar ao confronto, como nos mostra a citação. Divergir é possível e desejável, porém o risco está na tentativa de anulação do oponente. Quando traduzido essa reflexão para o cenário político brasileiro, as evidências são grandes. É a radical imposição que gera a resistência e compromete a todos, mesmo que de um lado do polo ceda à chantagem, o comprometimento pode acontecer, como no caso do filósofo grego Sócrates.

\section{ELITE, DOMINAÇÃO E DEMOCRATIZAÇÃO}

Para compreender as primeiras mudanças no comportamento do Brasil Colonial e a sua transição do rural para o urbano, a obra mais relevante a se estudar é "Sobrados e Mucambos" de Gilberto Freyre. A partir dela que Jessé Souza traduziu muito do que aconteceu naquele período da 
história, atualizando-a. Ele utilizou-se das informações em Freyre, mas trouxe novas evidências que clarificam a relevância daquela obra. Acrescentou dizendo que o processo de modernização do Brasil, na verdade, iniciou a partir de 1808 , porém a sua consolidação foi a partir de 1930 . O setor urbano e comercial tomou a direção do país naquela ocasião e agora está transferindo-o, ao conglomerado industrial, como se pode ver na citação.

O Estado autoritário e modernizador, que se consolida a partir de 1930, não inicia o processo de modernização brasileiro, que começa já em 1808, como vimos, mas o põe efetivamente num outro patamar. A partir dele, o processo de modernização brasileiro passa a ser comandado mais pelo surto urbanizador e comercial, como no século XIX, mas, agora, pela industrialização. (SOUZA, 2018, p. 219).

Quando se fala na elite brasileira e a sua intencionalidade, é preocupante, e, se o autor de a Elite do Atraso tiver razão, o caso é de resistência mesmo. Para ele “... O que a Lava-jato e seus cúmplices na mídia e no aparelho de Estado fazem é o jogo de um capitalismo financeiro internacional e nacional ávido por "privatizar" a riqueza social em seu bolso. (SOUZA, 2017, p. 12). Seria essa a dramática situação que o país está vivendo? A elite estaria polarizando o contexto social e, por essa razão, do outro lado do polo estaria na resistência social? Mas, por que há tantos oprimidos da sociedade contra determinadas circunstâncias desse embate? Seria a falta da informação da realidade que estamos mostrando aqui?

As interrogações requerem muitas reflexões e para polemizar o diálogo neste texto convido-o a observar a reflexão feita em "Subcidadania brasileira: para entender o país além do jeitinho brasileiro, 2018", também de Jessé Souza. Na obra, ao apresentar Pierre Bourdieu e a reconstrução da teoria crítica, ele mostra o conceito de "habitus". Segundo Souza é preciso desconstruir, desmascarar a base dominante que causam a aceitação e legitimação dos fatos. Seria o "habitus" proferido em Bourdieu refletido por Souza, que causa a "magia social" e dá o tom a essa valsa social? Talvez esteja aí o primeiro passo para dar resposta às interrogações que antecedem a este parágrafo. “... É o habitus que produz a "mágica social” que faz com que pessoas se tornem instituições feitas de carne. Neste sentido, o filho mais velho e herdeiro, o homem por oposição à mulher, são diferenças instituídas que tendem a se transformar em distinções naturais". (SOUZA, 2018, p 81).

Pertinente também é a possibilidade demonstrada por Souza com o culturalismo que “tornou uma espécie de senso "comum internacional"”, como diz o autor. Além do poder de persuasão de corporações, ou de intelectuais do país que impulsionam interesses restritos a um grupo privilegiado da sociedade, aparece, na reflexão feita por ele, uma força externa. Um modelo a ser seguido e a exemplar comparação a outros países, obviamente em desvantagem, tendo-o, como exemplo de perfeição em oposição à imperfeição dos comparados. Esse fator ideológico pode ter contribuído em escala relevante para a submissão e a magia social sinalizada por Bourdieu.

O culturalismo tornou-se uma espécie de "senso comum internacional" para a explicação das diferenças sociais e desenvolvimento relativo ao mundo inteiro. O instante de ouro do culturalismo foi a entronização da teoria da modernização produzida especialmente nos EUA do segundo pós-guerra e disseminada a partir daí no mundo inteiro. Ela explicava precisamente o porquê de algumas sociedades serem ricas e adiantadas e outras pobres e atrasadas. Os EUA foram assim transformados em modelo exemplar para o mundo, e comparações empíricas com outros países foram realizadas em escala massiva para demonstrar 
que os EUA eram o paraíso na terra e todos os outros países, realizações imperfeitas desse modelo. (SOUZA, 2017, p 16).

Viu-se que se trata de um culturalismo falso, cientificamente, mas seu poder é relevante, tanto quanto, "o poder do racismo da cor da pele", como diz o sociólogo brasileiro. Aparece, neste caso, a distinção de superioridade de uns, em detrimento da inferioridade de outros, tudo isso para legitimar a dominação. É por essa razão que o autor persiste em falar na mesquinhez da elite brasileira e no ataque "legítimo", na ótica da elite, a qualquer iniciativa popular, mesmo que seja, indiretamente. $\mathrm{O}$ país tem um mercado monopolizado por atravessadores financeiros que acusa o Estado e se torna invisível aos olhos dos cidadãos pouco politizados.

As consequências política e social dessas tiranias privadas, quando se transmite da esfera da família e da atividade sexual para a esfera pública das relações políticas e sociais, tornam-se evidentes na dialética de mandonismo e autoritarismo de um lado, mais precisamente do lado das elites, e no abandono e no desprezo das massas por outro. (SOUZA, 2017, p. 54).

Neste caso, aparecem as consequências políticas e sociais que estamos mostrando em nossa lógica de raciocínio desde o início deste trabalho. É o cenário político mais contundente que poderia acontecer, onde uma força, ou, um polo se esforça para massacrar e legitimar sua ação e o outro, se vendo na necessidade de resistir a tamanha brutalidade que atinge a uma maioria indefesa. Há uma demanda em jogo que é preciso ser esclarecida a quem não detém o conhecimento científico e essa demanda deve ser assumida por quem se vê como a voz e a resistência destes infelizes que são influenciados culturalmente para a distorção. Esse é o grande desafio para os que opõem ao sistema, resistir a uma estrutura organizada e poderosa sem poder contar muito com as massas que em geral é manobrada.

É nesta perspectiva que o leitor conseguirá entender o rumo a que queremos chegar. Não se trata de algo simples, mas trata-se de possibilidades legítimas que devem ser externadas à sociedade. Somente a desconstrução da ideia impositiva impetrada pelo sistema de domínio social é capaz de reverter essa situação. As pessoas sentem o peso dos problemas sociais, sofrem com a demanda na sociedade, mas não percebem o jogo que a história deixou de revelar como conhecimento, a educação e alguns educadores que buscaram revelar essa trágica situação, foram intimidados e até torturados em muitos dos casos. Evidentemente, houve lutas e lutas distintas, muitas conquistas promissoras, razão pela qual ainda há resistências, bem como, a força para tais reflexões.

\section{POPULAÇÃO CIVIL, ORGANIZAÇÃO SOCIAL E DEMOCRACIA}

Não dispomos de elementos para desmistificar a luta de classe no país, o objetivo exposto aqui, é no sentido de afirmar que elas existiram e continuam vivas na sociedade, bem como, as distorções ideológicas que intimidam a muitos. A sociedade brasileira, como tantas outras, é constituída de classes, onde, em geral, há uma elite que possui todos os privilégios, controlam o capital e com ele outros componentes sociais, como os meios de produção, a comunicação, a cultura, fortificando-se cada vez mais na era neoliberal, eles avançam no político e articulam, na perspectiva da globalização, um projeto mais ambicioso. Não é difícil ver sinais de que já existem influências em 
decisões no campo jurídico, motivo para enorme preocupação.

Também há uma classe média que as vezes sonha se tornar mais poderosa e passar para o campo majoritário, ou, se contenta com os privilégios que possuem mantendo o equilíbrio e a ordem social. Essa classe garante a parte burocrática que não estava consolidada na época da Casa Grande e Senzala estudada por Freyre e, também, mencionada em Sobrados e Mucambos. Essa estrutura ganhou a sua consolidação, a partir do advento dos Bacharéis. Mas o que importa aqui, é perceber que, independente da pouca oportunidade, das distorções e manipulações, sempre houve um ser criativo que buscou olhar para o lado de uma maioria explorada desse país. 0 Estado se estruturou, se fortificou, mas a população civil buscou questionar o poder, mesmo na tentativa de esconder, ou distorcer a verdadeira história do país, muitos cidadãos não deixaram se manipular.

Das lutas de classe, nasceram algumas conquistas democráticas no país, o cidadão brasileiro ganhou diversos direitos que antes não existiam, um deles é a "oportunidade de expressão" censurada em determinados momentos na história, mas muito eficaz para possibilitar a quem possui informação, traduzir ao leigo o jogo jogado pelo sistema dominador. Considerando que há uma elite no país, entende-se que há uma classe trabalhadora, que trabalha na geração da riqueza e pensamentos opostos, obviamente. A criatividade faz com que muitos críticos questionassem o cenário caótico da sociedade de acordo com a época e situação. Um desses personagens que faz sentido destacar por ter sido um defensor da educação e crítico à elite, é o brasileiro Paulo Freire que, mesmo após a sua morte, ainda continua sendo alvo de críticas por incomodar o sistema elitista brasileiro.

\footnotetext{
A violência dos opressores, que os faz também desumanizados, não instaura uma outra vocação - a do ser menos. Com distorção do ser mais, o ser menos leva os oprimidos, cedo ou tarde, a lutar contra quem os fez menos. E essa luta somente tem sentido quando os oprimidos, ao buscarem recuperar sua humanidade, que é uma forma de criá-la, não se sentem idealisticamente opressores, nem se tornam, de fato, opressores dos opressores, mas restauradores da humanidade em ambos. E aí está a grande tarefa humanista e histórica dos oprimidos - libertar-se a si e aos opressores. (FREIRE, 2005, p. p 32.33).
}

Freire foi capaz de mostrar que a violência causada pelo opressor não é boa nem para ele mesmo, pois ao desumanizar o outro, ele se faz menos. É a opressão que faz com que o oprimido se defenda e, neste caso, convido-o a lembrar o assunto proposto para discutir neste artigo voltado à polarização. Há muitas críticas quanto ao embate dos polos ideológicos no país. Seria necessário este embate, ou alguém está exagerando na sua resistência? Se há exagero de alguma parte, por que motivo a sociedade não entende a resistência? Qual dos polos teriam maior razão para lutar? Qual dos polos realmente preocupam com a sociedade, como o meio ambiente, com o humano? Estas são interrogações que merecem reflexão do leitor.

Considerando o pensamento em Souza (2018), que também é crítico à elite e, o hábitus estudado por ele, em Bourdieu, o “... sistema de estruturas cognitivas...” introjetada nas pessoas desde muito cedo é, sem dúvidas, um dos motivo da passividade com que muitos aceitam a situação, por mais que eles sofrem os danos e lamentam a má sorte, aceitam-na, passivamente. O sonho da "igualdade de oportunidade" faz com que muitos se acomodassem e vivessem toda a sua história na expectativa de que um dia alcançaria seus objetivos. Se Jessé faz as suas críticas ao contexto político/ideológico do país, a partir da ótica da Sociologia, na ótica da educação, Freire mostrou a 
desconexão da educação brasileira no ponto de vista ideológico, despolitizado. Trata-se de tempos diferentes e realidade sem coerência social capaz de garantir ao cidadão a sua libertação.

\section{A TECNOLOGIA}

O mundo vive uma nova era e o país também. Além do "avanço" industrial nos diversos sentidos e as conquistas tecnológicas, há um setor que merece reflexão e vamos mencioná-lo aqui. Trata-se das TICs²! Essa nova modalidade trabalha intensamente, atende aos interesses do público, mas discretamente influencia na opinião, induz as pessoas quando há interesses em jogo e justifica-se mostrando a sua eficácia do ponto de vista da "evolução". De forma objetiva vamos perpassar por esse tema que, obviamente, requer maior compreensão técnica, mas a superficialidade dos argumentos é suficiente para clarificar o raciocínio. Tomemos como exemplo Ribeiro (1995), ao descrever o encanto dos índios que viram os europeus chegando na Ilha que mais tarde chamaria Brasil utilizou-se da sua visão mítica, entendendo aqueles humanos que ali chegaram, como enviados do supremo. Os nativos viram neles o "deus sol" e essa influência mítica ajudaria na sua sedução e entrega ao explorador.

Não diferente, após mais de cinco séculos estamos vendo o entusiasmo dos humanos aos avanços tecnológicos que podem traí-lo por influências dos que querem o controle e o domínio ideológico. Esse "endeusamento" preocupa e impulsiona a reflexão proposta aqui, pois a situação desproporcional entre um conhecimento e o outro, além da intencionalidade, está mais favorável ao sistema financeiro capitalista e não ao social, ao trabalhador. Buscamos em Kemp (2013), um estudiosos da teologia, alguns conselhos úteis às famílias onde o autor fala na contribuição da mídia, na sua eficácia, mas mostra as contribuições negativas que ela pode proporcionar, exatamente o endeusamento, a falta de esclarecimento sobre a intencionalidade discutida aqui, que põe as pessoas do momento atual em risco.

\section{OS BENEFÍCIOS}

É preciso o bom senso para compreender a eficácia e a intencionalidade da evolução dos últimos tempos. A lógica evolutiva tecnológica tem importância ímpar, o preocupante é a intencionalidade de corporações que fogem a regra, transformam o que deveria ser um bem, em um mecanismo malicioso, desumano. É a desumanização no uso dos recursos tecnológicos que deve ser refletida. A razão proporcionou a evolução, mas a evolução produz ações que a descaracteriza, desconstruindo sua eficácia e esse raciocínio deve estar no debate do momento. Não é preciso ser filósofo para perceber com quanta irracionalidade ocorre determinadas ações na era das "evoluções". De um lado, é possível ver a tecnologia na comunicação, a evolução na medicina, a corrida espacial, etc, e, do outro, a pressão psicológica na população leiga, a destruição do meio ambiente e o descaso social. Quanto drama!

A passagem da lógica da produção capitalista das mercadorias materiais para as mercadorias simbólicas é o momento decisivo da decadência da reflexão racional como um recurso societário. O capitalismo organizado expande-se da esfera de produção de bens materiais para a produção industrial de bens simbólicos, constituindo aquilo que T. W. Adorno havia chamado de "indústria cultural”. (SOUZA, 2017, p. 123). 
Considerando a opinião do sociólogo Souza é necessário estar atendo nas mudanças de lógica no sistema capitalista que passa da concepção de mercadorias, portanto, material à mercadoria simbólica, ou seja, a indústria cultural apontada por Adorno in. Souza (2017). Dowbor, por sua vez, em “A era do capital improdutivo (2017), usa o campo da economia e mostra como o sistema provoca a instabilidade econômica e impede a sua regulação com manobras políticas. Segundo o autor, é em função da instabilidade econômica que o Estado vira refém dos gigantes financeiros. Esta é a forma de pressão que obriga aos que percebem e querem o bem local, o bem social, resistir e se manter no polo de oposição à elite que quer fazer o jogo financeiro no país a sua moda.

Por outro lado, um estado ciente do jogo em questão e atento à necessidade real do país, pode adotar medidas na mesma celeridade dos avanços, ou aproximado, emitindo informações às massas, à sociedade. É possível fazer melhoria na educação e o embate contra o sistema ávido a "engolir" todos os que trabalham. São os recursos tecnológicos criados para a manobra que podem reverter-se em novas criações, se forem bem utilizados pelas massas. O economista Dowbor defende a tese dessa mudança. No livro, “O Capitalismo se Desloca (2020)" ele acredita na virada do jogo e, se a sua ideia tiver sucesso, poderá sim, haver uma mudança substancial. Neste caso, apareceria o benefício real da evolução tecnológica, especialmente, a partir da comunicação e mais uma vez, a arte em jogo seria útil para revolucionar o social.

\section{O COMPROMETIMENTO}

Observando tudo o que foi apresentado até aqui, bem como, a ideia em Souza de desconstruir o culturalismo racista conservador do país, vê-se que o artigo possui um tema pertinente. Além da análise interna feita pelo autor, a grande novidade ideológica seria a popularização das informações para que todo o cidadão tenha como entender a realidade em que ele vive. O embate ideológico polarizado no país é fruto de uma dimensão maior, pois atualmente, o local está atrelado ao global. $\mathrm{O}$ bom seria se as massas populares dos países explorados percebessem como o poder controla as ideias, é bastante possível que elas desmontariam toda a estrutura global como em um passe de mágica, pois a estrutura global é forte no controle do local, desmontando esta, acreditase que o global se esfacelará, automaticamente.

Veja o que diz Souza: ... O domínio da elite sobre a classe média é simbólico e pressupõe convencimento. O domínio sobre as classes populares baseia-se, ao contrário, mais na repressão e na violência material. Souza (2017, p. 115). Se houver a percepção das classes populares, a partir dos veículos que foram criados para a sua manobra e, se essas classes o usarem a seu favor, o potencial do sistema mudará, mesmo tendo como trunfo, o uso da força. Quanto a classe média, ela só se mostra forte sendo sustentada e manobrada pela elite, sem a sustentação e manobra que muitas vezes é a única alternativa para se manter com privilégios, ela se esfacelaria e muitos membros migraria na direção do social. São as amarrar que impede muitos se posicionar a favor dos desprovidos no meio social.

A educação é um caminho promissor e por essa razão cabe ao educador desenvolver um novo paradigma, desvendando articulações impetradas pelo sistema. Se o capitalismo se deslocar como prevê Dowbor (2020), o impulso dessa mudança chegará à educação e contribuirá muito. 
Quanto a opinião do educador brasileiro, viu-se que: "Freire, na sua práxis político-pedagógica se opõe a um paradigma de educação que busca domesticar a consciência, para adaptá-la ao mundo. Critica a concepção de educação como ação cultural para a domesticação...". Schwendler (in. Souza, 2001, p. 105).

O grande comprometimento que o país se sujeitou em toda a sua história foi o fato de condenar quem foi crítico ao sistema dominante e privilegiar corporações que dedicaram ao sistema de dominação elitista. $\mathrm{O}$ desrespeito à crítica, do ponto de vista ideológico ao sistema, gerou muitos desconfortos sociais, confrontos, mágoas e sacrifício dos que a ele se apresentaram como opositor. A dura realidade histórica dá evidências dos desmandos ocorridos, o choque entre forças contrárias, mostram que o país viveu e ainda vive situações que merecem ajustes. Por um lado, se vê bilionários esbanjando privilégios e do outro, uma maioria sujeita a mendigar auxílio para sobreviver e garantir a sobrevivência dos filhos.

\section{O ILUMINADO}

Existiria um iluminado social, o salvador da Pátria. Esse iluminado seria a elite com seu projeto de inovação tecnológica capitalista globalizado, um projeto favorável as grandes corporações, ou seria quem defende e pertence a sociedade organizada nos seus processos de contraponto à elite? Por onde caminhar para encontrar uma saída, sabendo que há um embate polarizado? Quando o cidadão desperta para o drama social, ou, ele se informa melhor e entende as amarras do sistema, ou o bastante óbvio é que ele enfrente um caos psicológico. Naturalmente, quem começa a perceber o esquema ideológico articulado, fica confuso mesmo. Para escolher o lado a se posicionar, é importante pensar em si mesmo, na sua família e estudar os dois lados da "moeda social" em disputa. Pensando em você, na sua família, como parte do social, quem você ama e quer defender, analise a versão e o polo. Ele está favorável a você, ou aos projetos distantes da sua realidade?

É preciso ver que a elite tem um pensamento consolidado com base na sociologia, tanto quanto, a sociologia em Jessé Souza que condena as atitudes desta mesma elite. Não é difícil encontrar artigos mostrando os principais percussores da Teoria das Elites - Vilfredo Pareto e Gaetano Mosca. Ao leitor interessado sugerimos a leitura em "Ciências Políticas e Trajetórias sociais: uma sociologia história da teoria das elites. (1999)", de Mário Grynszpan. A exploração sempre existiu, mas a ideia concreta de dominação embasada por uma teoria favorável à elite se consolidou a partir dos referidos estudiosos da Sociologia apontados por Mário Grynszpan.

É importante entender que sempre houve debate em torno do poder, mas antecedemos a Pareto e Mosca para mostrar outro autor importante e crítico ao sistema capitalista, Kall Marx. Este pesquisador e crítico foi estudioso da forma estrutural do sistema, questionando-o, portanto, odiado pela elite até os dias atuais mesmo passando séculos da sua história. Gosto do debate em torno da alienação e feitichismo. Em (BERMUDO, 2015, p. 117), é possível ver que: Marx “... baseia-se na luta contra a alienação e o feitiche, os dois rostos amáveis da dominação..." e ambos, obviamente, ajudam nas articulações da elite brasileira, tanto a alienação quanto o feitiche, andam de mãos dadas nesse país. Através de Bermudo, destacamos dois feitiches para apresentá-los aqui: o feitiche da mercadoria 
e o feitiche do direito. No primeiro aparece “...a entrega de corpo e alma à "vontade" da mercadoria, ao seu movimento...”, (p.119), e, no segundo caso, a “... máscara da verdadeira função do estado...” (p.126).

\begin{abstract}
... O feitichismo funciona sempre da mesma maneira, encobrindo uma realidade, no duplo sentido de legitimá-la como natural ou como voluntariamente posta pelos homens, e de ocultar a outra realidade que suplanta, domina e impede de aflorar. Os direitos são, sem dúvidas, uma defesa dos indivíduos, inclusive dos mais frágeis, como a liberdade do mercado é uma proteção face aos terríveis vínculos de servidão; mas também, e ao mesmo tempo, os direitos são uma forma de dominação, pois respondem a uma necessidade do modelo econômico hegemônico que inelutavelmente tendem a reproduzir. Os feitiches são feitiches, e ainda que sejam tão belos como os direitos, escondem sempre alienação e submissão. (BERMUDO, 2015, p. p 129.130).
\end{abstract}

No campo social, especificamente o brasileiro, mas não só o brasileiro, encontram-se as complementações: “... Juntas, a demonização da política e do Estado e a estigmatização das classes populares constituem o alfa e o ômega do conservadorismo da sociedade brasileira cevado midiaticamente...". (SOUZA, 2017, p 136). De um lado, está claro que houve um jogo estratégico articulado a séculos e, do outro, atualizações e apoio midiático que continuam em evolução a cada dia, agora, com algoritmos mapeando as estratégias mais viáveis à manipulação ideológica. Ao trabalhador que busca se informar, resta a dupla jornada, conciliar trabalho e estudo para chegar ao conhecimento, somos prova disso.

Ainda, em Souza (2018) aparece uma novidade descoberta importante feita por Santo Agostinho, “... a noção de interioridade...”. Ele percebeu que: “... O conhecimento não é uma luz exterior lá fora, uma revelação, portanto, como era para Platão, mas é algo interior em nós mesmos, sendo antes uma criação que uma revelação". (SOUZA, 2018, p. 58). O problema parece estar no fato de tirarem a possibilidade desse interior fluir, reflexão que clarifica a muito do que foi refletido até aqui. o sucateamento ideológico do ser humano, que o manipula deixando de ser sujeito, faz com que diminua a sua força para externar o sentimento presente no seu interior, motivo de muitas explosões emocionais inconscientes.

Além disso há um fator de interesse pessoal, em muitos casos. Se considerarmos a opinião do grande pensador brasileiro que fala na "irresistível atração" do oprimido em relação ao opressor, por mais que o oprimido discorde da opressão, segundo Freire (2005), no fundo alguns a cultiva, isso ocorre mais fortemente com a classe média. O sonho da mudança de classe faz com que, na primeira oportunidade, o oprimido busca imitar o opressor e segui-lo na sua forma de ser e agir. Na verdade, há um drama social que impulsiona cidadãos ao sonho de ser o outro, para não ser a si mesmo e, neste caos social, muitos se perdem em suas ações. A reflexão apresentada aqui convida-o ao cuidado com as ações que podem reproduzir aquilo que se condena.

\title{
CONSIDERAÇÕES FINAIS
}

O artigo visou provocar ao leitor um despertar sobre o momento histórico que o país vive em seu "Cenário Político Brasileiro e a Polarização". Trata-se do contexto ideológico recente onde o país vive um dilema indefinido. O estudo em caráter bibliográfico analisou situações do passado contrastando-as com a realidade direcionando o leitor pensar no presente. Mostrou etapas de evolução antropológica e social no mesmo que de forma superficial. Se, de um lado, há um poder que 
quer a todo custo privatizar as riquezas sociais, do outro, há uma força que defende o Estado e a democratização das riquezas do país. No meio de todo esse processo, encontra-se os avanços tecnológicos que trazem benefícios aos polos distintos, mas ele está sendo disputado entre as tendências pela eficácia dos seus benefícios que pode atender a um, ou outro seguimento.

Portanto, o trabalho aqui apresentado sugere reflexão ao leitor entender a dimensão histórica e psicológica da sociedade para se ter uma ação racional, em caráter humano. Sabe-se que o momento de incerteza criado com o advento da pandemia na Covid 19, apesar do drama que o país está vivendo, serve de instrumento para a sociedade repensar a sua história. A perspectiva ainda é incerta, os dramas ideológico sociais também, mas os avanços tecnológicos, principalmente na comunicação está possibilitando muitas reflexões. Talvez tenhamos uma nova era de transição no contexto das sociedades. As turbulências ideológicas são claras e elas não estão somente no local, o seu caráter é global e estão cada vez mais evidentes.

Para entender o momento, o estudo perpassou pela origem social e antropológica dos brasileiros, mesmo na superficialidade, falou no sistema semifeudal e escravocrata, na transição do rural ao urbano e deste à industrialização. Não perdeu de vista a polarização entre a elite e a resistência social destacando o domínio e a democratização como pressuposto no embate, o uso da tecnologia pelos dois polos ideológicos onde há o consenso de ambos os lados sobre os benefícios, mas a preocupação com a tendência e risco do uso desses recursos, para enfim, sugerir ao leitor encontrar o melhor caminho a trilhar. Enfim, dado as resistências nos dois extremos e as possibilidades, esperase que o artigo sirva como fomento a novos debates estimule novas produções na perspectiva proposta aqui.

\section{REFERÊNCIAS BIBLIOGRÁFICAS.}

BERMUDO, J. M. Marx - da ágora ao mercado. Salvat. São Paulo, 2015.

CORTELLA, M. S. Viver em paz para morrer em paz: se você não existisse, que falta faria (interrogação). São Paulo: Planeta, 2017.

CARDOSO, F. H. Casa Grande \& Senzala: formação da família brasileira sob o regime da economia patriarcal. 48 a ed. Ver.- São Paulo: Global, 2003. Disponível em < https://docs.google.com/file/d/0B46vjiRI8hGuQzF2Y3hrSGVfRkk/edit > Acesso em 29/09/2020.

DOWBOR, L. A era do capital improdutivo: Por que oito famílias têm mais riqueza do que a metade da população do mundo? Autonomia Literária. São Paulo, 2017.

, L. O capitalismo se desloca: novas arquiteturas saciais. Edições Sesc: São Paulo, 2020.

DUSSEL, H. Ética Comunitária: Liberta o pobre. Tradução de Jaime Clasen. Vozes. Petróplolis, Rio de Janeiro, 1986.

FREIRE, P. Pedagogia do Oprimido. 42. ed. Rio de Janeiro: Paz e Terra, 2005.

, P. Pedagogia da Autonomia. Paz e Terra, 2004.

FREYRE, G. Sobrados e Mucambos. São Paulo: Global, 2004.

GRYNSZPAN, M. Ciências políticas e trajetórias sociais: uma sociologia histórica da teoria das elites. FGV: Rio de Janeiro, 1999.

KEMP, J. Pai inteligente influencia o filho adolescente - Se você não fizer, alguém o fará. Rio de Janeiro: Graça, 2017.

RIBEIRO, D. O Povo Brasileiro. A Formação e o sentido do Brasil. São Paulo: Companhia das letras, 1995.

SOUZA, A. I. Paulo Freire. Vida e Obra. São Paulo: Expressão Popular, 2001.

SOUZA, J. A Elite do Atraso: da escravidão à Lava-Jato. Rio de Janeiro: Leya, 2017.

, Jessé. Subcidadania brasileira. Para entender o país além do jeitinho brasileiro. Rio de Janeiro:

Rio de Janeiro, 2018. 